\title{
O grande carrossel urbano de Jacques Tati: a transição para uma modernidade urbana construída através dos filmes Mon Oncle e Playtime
}

Eliana Kuster*

RESUMO:O artigo atravessa dois filmes do mesmo diretor francês para, na transição entre eles, promover a compreensão da ideia de modernidade urbana, não apenas em sua morfologia, mas, em especial, no sentido sociológico. Os filmes de Tati mostram a transição entre duas cidades: vemos revezarem-se na tela a Paris do século XIX, com suas vielas estreitas, suas construções em tons pastel e sua mistura de usos e ocupação do território e uma Paris que já pertence ao século XX, com novas formas, nova tecnologia e novos comportamentos. Trataremos, a partir desses filmes, 0 tema de como os sinais do moderno se impõem, trazendo mudanças nas formas de comportamento, na estética e nas maneiras de viver.

Palavras-chave: cinema, cidade, modernidade

*Eliana Kuster é arquiteta, doutora em Planejamento Urbano e Regional (IPPUR / UFRJ e EHESS, Paris) e professora do Instituto Federal do Espírito Santo (IFES). E-mail: elianakuster@gmail.com; eliana@ifes.edu.br 
ABSTRACT: This article analyses two films by the same French director, in the transition between the two of them, in order to understand the idea of urban modernity, not only in their morphology, but in particular in the sociological sense. Tati's films show the transition between two cities: we can see on the screen the nineteenth-century Paris, with its narrow streets, its buildings in pastel shades and a mix of uses and occupation of territory and a Paris that belongs to the twentieth century, with new forms, new technology and new behaviors. We will see, in these films, how the modernity brings changes in the forms of behavior, aesthetics and ways of living.

Keywords: cinema, city, modernity

Meus filmes se parecem menos a filmes do que a janelas abertas. Se olharem atentamente, vocês poderão ver não uma sucessão de "gags", nem uma ocasião de se divertir, mas, mais que isso, a vida propriamente dita.

Jacques Tati

Playtime, o filme de Jacques Tati, termina com uma cena que pode ser tomada como a sua própria metonímia: ao redor de uma rotatória, em meio ao tráfego intenso de um dos novos bairros de Paris, carros coloridos circulam embalados pelo som de uma animada trilha sonora que nos remete a um espetáculo circense. Essa cidade moderna apresenta novos símbolos, Tati parece apontar. Aqueles antigos carrosséis tão comuns na Paris do século XIX, agora, no despertar de um novo tempo, permanecem existindo. Com novas formas, porém. Na metade do século XX, os carrosséis parisienses de Tati são formados por automóveis coloridos que circulam sem sair do lugar ao redor de uma rotatória urbana. Alguns elementos reforçam essa impressão: o elevador da oficina ao fundo suspende e abaixa seus carros como cavalinhos de brinquedo, as crianças nas calçadas seguram balões de ar, o vendedor de sorvetes e a música alegre parecem anunciar que o espetáculo urbano já está em andamento. A cidade é um circo, poderíamos perguntar? 
São muitas as metáforas que já foram utilizadas pelo cinema para abordar a cidade: de sinfonias a labirintos, tivemos, em épocas distintas, diretores diversos tratando o espaço urbano através de prismas que os permitiam aproximarem-se dos múltiplos aspectos existentes na urbe. Com Tati não acontece de forma diferente. Em Playtime, realizado em 1967, o cineasta francês avança na questão já levantada em seu filme de 1958, Mon Oncle1. Neste primeiro, era apresentada uma transição: do espaço urbano cujas feições e modo de vida ainda remetiam ao século XIX, para a cidade moderna, composta por residências totalmente automatizadas que irão determinar as rotinas de seus moradores, dotando-as de procedimentos tão racionalizantes quanto aqueles dos quais passa a se compor a arquitetura. Em Mon Oncle essas duas cidades ainda dividem o mesmo espaço, e permanece a dúvida: esse novo modo de vida vai conseguir se impor aos citadinos? Transitamos, ao longo do filme, pelas mãos de Tati, por uma cidade que parece ainda guardar fortes traços - morfológicos e sociais - do século XIX, com suas ruas estreitas e sujas, construções espremidas umas contras as outras e uma mistura de pessoas de classes sociais diversas ocupando o espaço público do bairro de periferia. Ao mesmo tempo, o filme nos joga em outra cidade, que parece ser a negação desta primeira: uma cidade pertencente ao século $X X$, com sua modernidade composta de automóveis de último tipo, equipamentos concebidos para realizar tarefas anteriormente desempenhadas por mãos humanas e relações sociais ditadas por uma polidez impessoal e pela construção de aparências que nem sempre se verificam verdadeiras.

Este foi o primeiro filme colorido realizado pelo diretor. Ele se apropria verdadeiramente da cor, utilizando-a não apenas como mais um elemento que irá conferir veracidade à cena. Ao invés disso, o cineasta, tal e qual um hábil pintor, manipula a sua paleta, selecionando para a sua cidade nova e reluzente as tonalidades mais fortes e impactantes, enquanto para o bairro antigo são reservados os tons pastéis. "A cor participa diretamente da ação, ela tem um lugar próprio, ela desempenha um papel. Ela atua. Ela propicia um riso de qualidade. Tati é o primeiro a lançar mão, no cinema, das dissonâncias coloridas", afirma Jacques Lagrange (apud GUERAND, 2007, p. 171), um dos analistas de seus filmes. O próprio diretor faz eco a essas palavras ao comentar sua inspiração para o uso das cores: 
As tonalidades que se encontram em um bairro moderno são totalmente diferentes daquelas de um antigo. Os verdes são mais luminosos, os amarelos, quase lâmpadas elétricas. Há uma espécie de eletricidade nas cores com as quais eles são pintados: são sobretudo os americanos a trabalhar sobre essa questão. Eles se utilizam enormemente das cores vivas. Ao contrário, nos pequenos bairros, eu tinha à minha disposição os tons de veludo velho. (TATI apud BAZIN e TRUFFAUT, 1958, p. 10)

O filme Mon Oncle, balança, portanto, como uma gangorra, entre essas duas cidades, a nova e a antiga. Tati parece expressar a ambiguidade entre esses dois modos de vida e se questionar: qual deles será o mais adequado? Qual deles prevalecerá? Em qual deles o homem encontrará os rumos de seu futuro?

Playtime é a resposta, nada otimista, a essas questões: ali, a cidade modernista já se apresenta como uma realidade inexorável. Não há mais questionamentos, não há mais volta, não há mais espaço para antigos personagens, como a vendedora de flores malvestida que ocupa a calçada ou para aquele que não conhece as formas precisas de se comportar nesse novo espaço, como o Monsieur Hulot brilhantemente desempenhado pelo próprio diretor. Apenas Hulot parece expressar um certo desconforto com essa cidade que não sabemos inicialmente se é Paris, Roma ou Nova York². Apenas ele parece ser capaz de entrar por uma porta aberta sem perceber que se trata de um elevador, e, ao sair em outro pavimento do mesmo prédio - exatamente igual àquele em que ele estava anteriormente - nos fazer rir com a sua perplexidade. Nós rimos com Tati, mas é um riso nervoso. Porque, na verdade, estamos rindo de nós mesmos e da nossa dificuldade de adaptação. É, no fundo, como se o homem que criou essa cidade e essa arquitetura modernas não fosse moderno o suficiente para usufruí-la. Semelhante a Narciso, que, como canta Caetano, "acha feio o que não é espelho," o homem urbano desse período ainda parece olhar estupefato para a sua criação, fruto do seu próprio desejo de moderna urbanidade, e que, subitamente, parece suscitar um inesperado estranhamento. Análogas às vassouras que Mickey Mouse faz despertarem para a vida no desenho animado de Disney, Fantasia, percebendo depois que não consegue manter o controle sobre elas, as cidades de meados do século XX parecem criaturas que escaparam dos desejos de seus criadores e ganharam toda uma vida e dinâmicas próprias, é o que parece nos dizer Tati, traduzindo, através da arte, as longas e férteis discussões que animaram a sociologia urbana ao longo desse período. 
A "casca" urbana e modernista que foi se depositando nos citadinos durante a primeira metade do século XX, e que neles foi construindo aos poucos uma sensação de familiaridade com essa cidade, ainda estava muito fina quando da realização do filme. Nesse sentido, basta um leve esbarrão do diretor para que ela se rompa e nos ofereça um vislumbre desse homem ainda aturdido com as profundas mudanças objetivas e subjetivas da modernidade.

É outro diretor, Jean Luc Godard, quem afirma que Tati "procura problemas onde eles não existem, e os encontra. Tati explora e revela os absurdos da assim chamada "normalidade" que, entretanto, de normal nada possui" (ALMEIDA, 2005)³. É precisamente dessa "procura de problemas" que se constrói a narrativa de Playtime. O mais visível: o problema da arquitetura moderna, transformada em Estilo Internacional, que iguala todas as cidades. Em uma das cenas do filme, Tati constrói uma passagem absolutamente emblemática disso ao apresentar, em uma agência de turismo, cartazes enfileirados que mostram, cada um, um país. O que se vê como imagem, porém, é exatamente o mesmo prédio composto de uma enorme e impessoal fachada de vidro, imediatamente reconhecível como pertencente ao Estilo Internacional. Há apenas alguns pequenos elementos diferenciadores que tentam conferir identidade a cada local. Assim, para o Brasil temos um índio e palmeiras; para o México, um sol asteca e uma pirâmide; e para a Inglaterra, um ônibus vermelho de dois andares. É de se perguntar por que os turistas que desfilam incessantemente nas cenas de Playtime viajam. Tati apresenta a resposta: viajam para ver aquilo que é, cada vez mais, sempre igual. A Paris dos monumentos, da Sacré Cœur, da Torre Eiffel e do Arco do Triunfo é deixada de lado em prol dessa Paris modernizada que poderia ser qualquer outra cidade ${ }^{4}$. Os reflexos desses ícones, porém, ainda aparecem, fugidios, nos painéis de vidro de que essa cidade nova é composta, como fantasmas que a assombram, como a evocar fugazmente o seu passado. A história não é importante nessa cidade que busca incessantemente o moderno: ela foge ao olhar e se esmaece nos reflexos da modernidade; esta sim, importante e universal. Segundo Meize Lucas,

A sociedade para a qual Tati lançou o seu olhar é um universo capitalista, em que Moda, Publicidade e Mercadoria regem as relações de valorização e desvalorização, definindo o que é novo e o que é antigo, e isso vale tanto para os objetos quanto para comportamentos e hábitos. Essa sociedade estrutura, portanto, uma linguagem com a qual os indivíduos devem operar. O cinema de Jacques Tati deixa bem claros os códigos que se vão definido na sociedade, e o faz por meio do discurso cômico. (1998, p. 36) 
Para reforçar tal sensação, o diretor nos faz entrar com Hulot em uma exposição que apresenta novos produtos de consumo. Ali estão vassouras munidas de lanternas ("ela permite varrer embaixo dos móveis" na justificativa do vendedor, que apresenta seu produto com todo um gestual que se assemelha ao de um mágico realizando um dos seus mais preciosos truques), portas que batem sem ruído (e o diretor apresenta brilhantemente o paradoxo: se batemos uma porta, esperamos o ruído, como a anunciar estrondosamente a nossa saída. Se ele não acontece, há algo de frustrante e inútil no gesto), e demais mercadorias que tentam somar aspectos novos a objetos já há muito conhecidos. Nas palavras de uma das turistas que visita os estandes de vendas: "é tudo americano!" Mas qual seria a graça se aqueles turistas são, eles mesmos, americanos?

É o historiador François Beguin quem vai examinar de perto um dos mais fortes desejos originados pela modernidade: o do conforto. $O$ autor assim o faz detendo-se sobre o operariado inglês de meados do século XIX e examinando como esse conceito, o de uma vida pontuada por elementos de comodidade, vai se enraizando como uma meta a ser atingida, primeiro pela burguesia, e logo a seguir por toda uma classe proletária que deseja se inserir nos valores deste novo momento histórico: um período no qual a distribuição do tempo já se faz tomando por base as horas distribuídas cronologicamente ${ }^{5}$ - dividindo-se muito claramente entre o tempo do trabalho e o tempo livre - e, mais que isso, um período no qual o cotidiano urbano começa a se impor como forma natural de vida, e a rotina de acontecimentos sucessivos em uma cidade passa a ser vista como o modelo de todo convívio coletivo. Em outras palavras, o conceito do que seja o social e de como se desenvolvem as suas dinâmicas passa a construir-se, cada vez mais, tomando-se por base o funcionamento de uma sociedade urbana.

Nesse sentido, temos, segundo Beguin, o surgimento de uma "nova ótica de salubridade", ou seja, uma nova percepção do que deva ser o "habitar" adequadamente - seja uma residência, seja uma cidade - criando, portanto, novas expectativas e novas demandas com as quais o morador médio das grandes cidades passará a operar. Passa a vigorar, portanto, um esforço realizado pelo próprio citadino para enquadrar-se em um sistema que, ao mesmo tempo em que lhe restringe alguns comportamentos, também Ihe acena com vantagens. Isso irá derivar-se em formas de autocontrole e autovigilância que se mostrarão muito mais eficazes do que 
qualquer sujeição externa ao indivíduo, facilitando a manutenção da ordem e dos comportamentos padronizados necessários a qualquer convívio coletivo 6 . "A partir do momento em que se tem o domínio sobre certas sequências de seu modo de satisfação corporal, este indivíduo pode muito bem se tornar o melhor vigilante de si mesmo", reforça Beguin, completando ainda: "se o conforto é uma arma poderosa, é porque ele atinge uma forma de bem-estar que ninguém tem meios de recusar [...]. O conforto é, portanto, um processo de invasão ao qual não se pode resistir". (1991, p. 47, 48) O conforto, desse modo, é transformado em um dos valores através dos quais se expressa a modernidade, juntamente com os de funcionalidade, eficiência e racionalidade. (LUCAS, p. 62) O que Tati parece nos mostrar em seu filme é a evolução desses conceitos, ou seja, de como esse processo de criação de uma rotina de comodidade funcional e eficaz, que se inicia em meados do século XIX através de medidas como fornecer água encanada e aquecimento às residências dos operários - naturalizadas pelo nosso olhar contemporâneo como "básicas" -, vai se desdobrar por todo um caminho que chega à criação de uma vassoura munida de lanternas.

No local que expõe os produtos, mais uma cena que metaforiza o discurso do filme. Somos apresentados à réplica de uma coluna grega. Percebemos um pouco depois que ela abre e se revela ser... uma lixeira! É uma cena simples, mas nela não há gratuidade: ela contém todo um depoimento de Tati sobre o seu tempo, e sobre toda uma sociedade do consumo que se anuncia:

A coluna perde seu status de objeto culturalmente nobre, de encarnação da beleza clássica e da graça arquitetural. [...] Esta degradação é particularmente rica de sentido. A coluna, sem dúvida, está associada aos dejetos, porque encontra-se, ela mesma, em ruínas. Nossa civilização não deseja senão o novo e cintilante. Ela não pode mais perceber a beleza. (EDE e GOUDET, 2002, p. 167)

A coluna poderia ser tratada como a metáfora da história, que, voraz, a tudo engole? Ou estaria significando o lugar atribuído à história nessa sociedade que se pretende tão "moderna"? Ficamos com as questões plantadas pelo diretor assombrando incomodamente a nossa mente. 
Prosseguimos na cidade de Tati, ainda acompanhando os problemas que incomodam o cineasta. E estes são muitos: eles tratam da diluição das fronteiras entre o público e o privado, nos mostrando as casas que são quase "vitrines" e que expõem o seu interior a qualquer um que transite pelas vias públicas. Na análise de Weinberg,

Esses aquários que exibem publicamente a intimidade das pessoas demonstram como a vida moderna se baseia em aparências. [...] Por essas fachadas de vidro acompanhamos a rotina semelhante dos moradores urbanos modernos: em todos os apartamentos as famílias reúnem-se na sala e ligam o televisor, no mesmo canal, à mesma hora. Esse quadro revela uma profunda crítica de Tati à forma como a TV vinha se impondo à sociedade moderna e ditando a rotina cotidiana dos habitantes dos grandes centros urbanos. (2005, p. 196)

Este mesmo material que permite a visão dos interiores e da privacidade dos moradores é um dos elementos centrais do filme: o vidro. Em vários momentos da película, somos colocados face aos seus paradoxos: ele propicia o olhar, mas impede o toque? ${ }^{7}$ Ele é o principal material que compõe o novo bairro, mas, ao mesmo tempo apresenta os reflexos da cidade antiga. Elemento símbolo da nova arquitetura desde meados do século XIX, os grandes panos de vidro parecem assumir, para Tati, um papel metonimizador da modernidade, na qual tudo é crescentemente exposto ao olhar, tudo vira algo a ser observado, ou, como iria definir Guy Debord (1997) no seu trabalho mais famoso, lançado no mesmo ano do filme, tudo se transforma em espetáculo.

Tati nos permite ver, através das suas grandes superfícies envidraçadas, a continuidade da crítica à padronização de vida que já havia sido iniciada por ele em Mon Oncle, onde, todos os dias, no mesmo horário, os personagens da família que habita o bairro novo da cidade se reúnem para assistir ao programa de um personagem com um nome bastante representativo: o professor Platov. Certamente não terá sido por acaso que a alcunha do professor midiático quase repete aquela do fisiologista russo Ivan Pavlov, que estudou o papel do condicionamento na psicologia do comportamento, desenvolvendo as teorias que passaram a ser denominadas por "reflexo condicionado." Nesse sentido, se a família de Mon Oncle encontrava-se no início deste processo, os personagens de Playtime já estão suficientemente "condicionados" para dirigirem-se todos no mesmo horário para a frente da tevê. O mito tão famoso da "caverna de Platão" 8 parece ter encontrado aqui o seu correspondente na vida moderna: 
as pessoas estão firmemente convencidas de que o que veem na tevê equivale às vivências reais. As sombras na caverna descritas pelo filósofo grego, na modernidade, são muito mais convincentes: possuem cor, som, se movimentam e narram histórias.

De certa maneira, poderíamos tentar comparar a divisão que o diretor institui ao longo do filme - entre o bairro moderno, que corresponde a todo um modo de vida novo, e a região mais antiga da cidade, que abriga velhos personagens urbanos e apresenta um cotidiano ainda pautado por velhos hábitos e comportamentos - à antiga divisão estabelecida por Benjamin Disraeli, antigo primeiro ministro inglês, quando falava a respeito das "duas nações" que ocupariam as cidades do século XIX (cf. BRESCIANI, 1985, p. 40): segundo ele, ali estariam, partilhando o mesmo espaço, os "ricos-civilizados" e os "pobres-selvagens", duas classes opostas em que uma se autonomeava como detentora do papel de representar a parcela civilizada e à outra era imputada a barbárie. Ao assim afirmar, a intenção de Disraeli era a de defender a sistemática criação de leis e ações sociais que propiciassem a inserção das classes trabalhadoras na lógica que guiava a parcela da população pertencente à classe mais elevada. Em outras palavras, que Ihes permitisse "civilizá-la". O filme de Tati, embora apresente uma divisão semelhante, vai tratá-la de forma diversa: o que o diretor parece querer nos mostrar é como a inserção crescente de comportamentos civilizatórios irá, em paralelo, retirar a essência da interação entre as pessoas, isolando-as e introduzindo em seu cotidiano uma série de procedimentos preestabelecidos, padronizados e sem conteúdo, incentivando o desenvolvimento de um modo de vida composto por uma grande parcela de artificialismo. $\mathrm{O}$ monsieur Hulot, que parece se encontrar tão à vontade em meio ao seu bairro popular, revela toda a sua inadaptação e o seu desconforto na casa nova de sua irmã e de seu cunhado. Já o filho destes, seu sobrinho, que em casa é uma criança solitária, apagada e sisuda, quando vai ao bairro popular com o tio se transforma em um menino alegre e brincalhão, que interage com outros garotos e faz molecagens comuns à sua idade.

Se em Mon Oncle esta situação ainda parece reversível, ou seja, se há um trânsito e uma permeabilidade possível entre esses dois tipos de espaço que compõem a cidade e essas duas formas de vida, em Playtime a modernidade já está tão estabelecida que não permite mais essa convivência. A cidade e o modo de vida antigos estão cada vez mais esmaecidos, em prol do novo, seja no espaço físico, seja nos comportamentos. 
Voltamos, portanto, a Playtime, seguindo com Tati no carrossel da "caça aos problemas" da modernidade urbana e encontramos mais um: o restaurante que será inaugurado naquela noite, mas no qual tudo parece estar inacabado. Durante a inauguração, os problemas se acumulam: à falta de funcionalidade de um espaço que se pretende funcional e aos elementos arquitetônicos que incomodam e/ou machucam os clientes e garçons, soma-se a precariedade das instalações que, feitas às pressas, revelam no desenrolar da noite o seu caráter inacabado, culminando com uma pane elétrica que deixa a todos no escuro e com um desmoronamento de parte dos elementos construídos. A festa continua, no entanto, com os fregueses do local "fechando os olhos" para os problemas que nos parecem tão evidentes e continuando a se divertir como se nada estivesse acontecendo. Talvez uma metáfora da atitude do homem do modernismo face aos problemas da própria modernidade? Só podemos especular a esse respeito, torcendo para não atribuirmos ao diretor intenções não apresentadas por ele.

Na verdade, Playtime não apresenta exatamente uma trama no sentido tradicional da palavra. Não nos são fornecidas maiores informações a respeito dos personagens, sequer sobre Hulot, o principal deles. Não há uma sequência lógica de acontecimentos que possamos identificar com clareza como etapas sucessivas do desenrolar de uma história. Tati trabalha claramente com um recorte da vida cotidiana, apresentando um dia na vida de Paris entrevisto por diversos olhares: do grupo de turistas, do morador habitual que ainda a estranha, o Monsieur Hulot, e de outros moradores que já estão mais habituados a ela. O que o interessa não são exatamente as pessoas, mas a interação destas com a cidade e com a vida na modernidade. Como em uma sinfonia urbana ${ }^{9}$, acompanhamos, durante as diversas horas do dia e da noite, os personagens e a sua vivência da cidade. O cineasta trabalha substituindo, segundo Meize Lucas, "a trama mirabolante por esses achados de observação, colocados por ele em imagens, costurados pelos fios do cotidiano. A ótica pela qual traça esses fios não é inocente; um problema e uma questão são postos". (1998, p. 41)

São vários, na verdade, os problemas e as questões que podem ser levantados a partir das situações apresentadas em Playtime: um dos principais é a transformação da cidade moderna em uma sucessão de lugares desprovidos de identidade - não sabemos, no início do filme, se o espaço mostrado é um hospital ou um aeroporto; o prédio da empresa para onde se dirige Hulot parece abrigar diversos tipos de atividade, mas os espaços são absolutamente iguais em todos os andares; a lanchonete pode ser facilmente confundida com uma farmácia. 
São muitos os exemplos ao longo do filme nos quais o espaço parece ser tão padronizado que tudo se torna igual, ou simplesmente parece apresentar signos que remetem para outra percepção de sua finalidade. O cineasta antecipa o raciocínio de Marc Augé (2005) que em finais do século XX vai nomear este fenômeno e os espaços criados por ele como "não lugares". Segundo ele, a hipermodernidade caracteriza-se por três tipos de transformação fundamentais: no tempo, no espaço e no indivíduo. Tati, muitas décadas antes, lança o seu olhar em direção a esses três elementos, tentando detectar e explorar essas transformações. 0 cineasta, enfim, ainda que não intencionalmente, parece deixar no ar uma pergunta: afinal, para que serve uma cidade? Se a intensa aceleração da circulação de corpos e mercadorias tem por consequência a crescente dificuldade do acontecimento do encontro com o outro ou seja, algo que, historicamente, sempre foi uma das principais características e atrativos de uma cidade - por que os homens ainda se reúnem para viver coletivamente? O diretor não apresenta uma resposta a essa questão, mas ela permanece incomodamente em nós, mesmo após sairmos da sala de projeção. Ele nos faz rir ao longo de suas películas, mas, na verdade, rimos de nós mesmos e esse tipo de riso nunca é confortável.

Uma das histórias bastante conhecidas a respeito do filme e da sua repercussão refere-se a um menino, que, após ver o filme, enviou uma carta ao diretor na qual dizia que, ao sair do cinema, a impressão que se tinha era a de que o filme continuava nas ruas. (apud LANDROT) Nesse sentido, teríamos o contrário daquela situação narrada por Hitchcock, que dizia que seu trabalho era simplesmente a habilidosa construção de uma fantasia. (TRUFFAUT, 1986) A qualquer momento, o espectador do filme poderia segurar nos braços de sua poltrona e se lembrar que aquilo que se vê na tela é apenas luz e sombra: ilusão. Mas, continuava Hitchcock, se ele fizesse seu trabalho de forma bem feita, o espectador poderia se esquecer que sua poltrona tinha braços. Tati parece trabalhar com a inversão disso: em seu filme, o espectador levanta e leva consigo os braços da poltrona. O filme continua, em cores e sons surpreendentemente vívidos, na rua, em qualquer rua de uma grande cidade.

Artigo recebido em outubro de 2013, aprovado em novembro de 2013 e publicado em dezembro de 2013. 


\section{Notas}

1 É inevitável estabelecer a relação entre os dois filmes, e não apenas no plano de continuidade temporal e histórica da narrativa que gravita em torno de questões semelhantes. A própria concepção de Playtime está ligada a Mon Oncle, como descrevem Ede e Goudet: "Entre 1959 e 1960, as numerosas viagens ligadas à apresentação de Mon Oncle fizeram de Tati um frequentador assíduo de aeroportos internacionais. Ele aproveitava o tempo para registrar e acumular observações. A arquitetura moderna que se organizava como um cenário, colocando em cena mercadorias e bens de consumo (farmácias, supermercados, grandes lojas), mas também as atividades humanas nos locais públicos nos quais o indivíduo está exposto aos olhares. O espaço público se torna um puro espaço de representação no qual se encontra excluída toda convivialidade. Esta característica não escapou a Tati, atento ao mundo que se transformava ante seus olhos". (2002, p. 38) Como podemos constatar, o espaço público e a sua transição rumo à modernidade - que já eram questões para o diretor quando da realização de Mon Oncle - vão guiar a sua percepção, afinando-a rumo às abordagens mais complexas e críticas que ele irá construir em Playtime alguns anos depois.

2 As cenas iniciais de Playtime, não por acaso, se passam em um aeroporto, o "não lugar" (AUGÉ, 2005) por excelência, que exclui toda possibilidade de convívio e apresenta-se monotonamente igual - ou bastante semelhante - em todas as cidades do mundo.

$3 \mathrm{E}$, apenas como uma curiosa coincidência, podemos lembrar que seu nome original, de origem russa, Tatischeff, tem por significado "caçador de ladrões" (tat-ladrão e isch - raiz do verbo procurar). Tati o modificou, retirando a sílaba final, para deixar de lado o "chef", incompatível com seu gosto pela independência e sua recusa à submissão. Mas também para escapar a uma etimologia desagradável: "il ne supportait pas l'idée de s'appeler Jacques Policier". (“Ele não suportava a ideia de se chamar Jacques policial”, Landrot, p. 6)

4 E é importante lembrar que Tati realiza seu filme antes da construção de La Défense, o bairro que se tornará a metonímia dessa Paris modernizada. Na verdade, para a realização de Playtime o diretor fez construir toda uma cidade cenográfica, totalmente moldada nos padrões morfológicos que seriam, pouco depois, os mesmos utilizados para o novo bairro de Paris.

5 Em oposição ao tempo definido como "natural", ou seja, pautado pelas atividades humanas dispostas de acordo com as condições da natureza. Os gregos antigos tinham duas palavras para designar o tempo: chronos e kairos. O primeiro refere-se ao tempo cronológico, ou sequencial, enquanto o último é um momento indeterminado no tempo em que algo especial acontece. Pode-se afirmar, de forma bastante simplificada, que chronos é o tempo humano, portanto, medido e descrito contemporaneamente em unidades de anos, dias, horas e suas divisões. Já kairos seria o tempo divino, o tempo vivido, subjetivo, que não é passível de medições.

6 Michel Foucault irá denominar esse processo através do qual o controle disciplinar "migra" do exterior para o interior do indivíduo, de "docilização", afirmando: "O corpo humano entra numa maquinaria de poder que o esquadrinha, o desarticula e o recompõe. Uma "anatomia política", que é também igualmente uma "mecânica do poder", está nascendo; ela define como se pode ter domínio sobre o corpo dos outros, não simplesmente para que façam o que se quer, mas para que operem como se quer, com as técnicas, segundo a rapidez e a eficácia que se determina. A disciplina fabrica assim corpos submissos e exercitados, corpos "dóceis". A disciplina aumenta as forças do corpo (em termos econômicos de utilidade) e diminui essas mesmas forças (em termos políticos de obediência). Em 
uma palavra: ela dissocia o poder do corpo; faz dele por um lado uma "aptidão", uma "capacidade" que ela procura aumentar; e inverte por outro lado a energia, a Potência que poderia resultar disso, e faz dela uma relação de sujeição estrita. Se a exploração econômica separa a força e o produto do trabalho, digamos que a coerção disciplinar estabelece no corpo o elo coercitivo entre uma aptidão aumentada e uma dominação acentuada". (FOUCAULT, 2002, p. 119)

7 E aqui, mais uma vez , Tati se vale da "inadaptação" de Hulot a essa realidade contemporânea. O personagem vê, do outro lado do saguão de um prédio empresarial, o executivo com o qual deseja falar, mas encontra-se incapaz de atingi-lo, impedido pelas diversas camadas de vidro que os separam. O mesmo executivo, em outro momento do filme, avista Hulot e tenta chamá-lo e chegar até ele, mas acaba dando uma forte pancada em uma das muitas paredes de vidro do edifício.

8 Platão descreve na obra intitulada A República (livro VII), o mito, ou alegoria da caverna. Trata-se da exemplificação de como podemos nos libertar da condição de escuridão que nos aprisiona através da luz da verdade. Ele imagina um muro bem alto separando o mundo externo e uma caverna. Na caverna existe uma fresta por onde passa um feixe de luz exterior. No interior da caverna permanecem seres humanos, que nasceram e cresceram ali. Estes ficam de costas para a entrada, acorrentados, sem poder locomover-se, forçados a olhar somente a parede do fundo da caverna, onde são projetadas sombras de outros homens que, além do muro, mantêm acesa uma fogueira. Os prisioneiros julgam que essas sombras sejam a realidade. Um dos prisioneiros, porém, decide abandonar essa condição e fabrica um instrumento com o qual quebra os grilhões. Aos poucos vai se movendo e avança na direção do muro e o escala; com dificuldade enfrenta os obstáculos que encontra e sai da caverna, descobrindo não apenas que as sombras eram feitas por homens como eles e, mais além, todo o mundo e a natureza.

9 As sinfonias urbanas são um tipo de abordagem fílmica bastante utilizado no início do século XX para apresentar a rotina das grandes cidades. A sua estrutura, em geral, acompanha um dia inteiro do cotidiano de uma cidade, mostrando as diversas atividades e os diversos personagens que a compõe. A mais conhecida das sifonias urbanas é Berlim, sinfonia de uma grande cidade, do cineasta alemão Walter Ruttman, realizada em 1927. A ideia por trás de uma sinfonia parece ser a de, ao estabelecer a comparação entre o espaço urbano e a música, mostrar que ambos - a cidade e a sinfonia - necessitam de um equilíbrio entre ações e tempo para que seja possível o seu acontecimento. Ou seja, tanto na sinfônica quanto no espaço urbano, é necessário que cada participante esteja ciente a respeito do seu papel e da hora certa de sua atuação. Poderíamos arriscar afirmar que o monsieur Hulot de Tati representa a dissonância nessa sinfonia tão bem ensaiada pelos outros personagens urbanos. É através dele que conseguimos perceber as incongruências, os paradoxos e as formalidades risíveis do modo de vida da modernidade urbana.

\section{Referências}

AUGÉ, Marc. Não-lugares: introdução a uma antropologia da supermodernidade. São Paulo: Papirus, 2005.

ALMEIDA, Paulo Ricardo. Parade. Contracampo, Revista de Cinema, n. 73, julho 2005.

BEGUIN, François. As maquinarias inglesas do conforto. Espaço \& Debates (NERU), n. 34, 1991. 
BRESCIANI, Maria Stella. Metrópoles, as faces do monstro urbano das cidades no século XIX. Revista Brasileira de História, São Paulo (ANPUH, Marco Zero), v. 5, n. 8 e 9, 1984-1985.

DEBORD, Guy. A sociedade do espetáculo. Rio de Janeiro: Editora Contraponto, 1997.

EDE, François e GOUDET, Stephane. Playtime. Paris: Cahiers du cinéma, 2002.

FOUCAULT, Michel. Vigiar e punir: história da violência nas prisões. Rio de Janeiro: Vozes, 2002.

GUERAND, Jean-Philippe. Jacques Tati: biographie. Paris: Galimard, 2007.

LANDROT, Marine. Tati: un drôle de numéro. In: Tati: quoi de neuf M. Hulot? Télérama hors série. Paris: Fondation Gan pour le cinéma, s/d.

LUCAS, Meize Regina de Lucena. Imagens do moderno: o olhar de Jacques Tati. São Paulo: Annablume, 1998.

WEINBERG, Juliana. A cidade transparente. In: NAZARIO, Luiz. A cidade imaginária. São Paulo: Perspectiva, 2005.

BAZIN, André e TRUFFAUT, François. Entretien avec Jacques Tati. Paris: Cahiers du cinéma, 1958.

TRUFFAUT, François. Hitchcock/Truffaut. São Paulo: Editora Brasiliense, 1986. 